\title{
Un equipo interdisciplinario al servicio de la comprensión del fenómeno religioso
}

La reciente inauguración del Centro de Estudios de la Religión, el jueves 5 de noviembre de 2015, dio paso a la discusión sobre el momento académico que vive nuestro país, demuestra la serenidad y actitud de diálogo propicia para establecer discusiones y propuestas de trabajo interdisciplinario en torno al fenómeno religioso.

La llamada interdisciplinariedad, entre otras cosas, avala la efectividad en el tratamiento de problemáticas complejas, que al ser tratadas desde la exclusividad de una disciplina no permiten una exploración y comprensión enriquecida y nutricia para la vida universitaria, de ahí que uno de los ejes de desarrollo para el próximo quinquenio en nuestra casa de estudios sea la interdisciplina para los grandes desafíos "Es crucial volver a mencionar la necesidad y aspiración de un mayor diálogo e integración entre las ciencias, las humanidades, las artes y la búsqueda de sentido a partir de la Teología" (Plan de desarrollo UC 2015-2020)
El plan de desarrollo de la universidad dota de una peculiar centralidad a la Teología como ciencia que aúna el saber, sitúa y contextualiza al fenómeno religioso o las ciencias de la religión como un espacio más de discusión entre las disciplinas. La tendencia a nivel mundial ha dado lugar a la creación de departamentos, institutos, cátedras, etc. centrados en su estudio, y donde interactúan las distintas disciplinas que se ocupan de las religiones: historia, sociología, psicología, filosofía, fenomenología, ecología, antropología, derecho, estética, etno-historia, geografía, teología, etc. Cautelar la comprensión del fenómeno religioso de manera interdisciplinaria e interreligiosa es propio del mundo anglosajón y europeo, sin embargo, la constitución del naciente Centro de Estudios de la Religión UC (CERUC) es una iniciativa pionera en Latinoamérica que da respuesta a dicha inminente necesidad en nuestro país y más allá de sus fronteras, aportando a generar conocimientos y reflexiones sobre 
la incidencia de la religión en las manifestaciones culturales e identitarias de Chile y Latinoamérica.

De lo mencionado se desprende la misión de nuestro Centro que consiste en promover y articular diversas actividades de investigación, docencia y difusión en vista de una mejor comprensión de la religión en nuestra cultura. Desde una perspectiva académica interdisciplinaria, busca conocer y comprender las peculiaridades que presenta el fenómeno religioso en Chile y América Latina, contribuyendo así a un fundado análisis e interpretación de una cuestión que interesa tanto a los individuos como a la sociedad.

$\mathrm{La}$ interdisciplinariedad del Centro de Estudios de la Religión lo constituye la misma riqueza y complejidad de la religión, que no permite que ella sea plenamente comprendida desde una sola mirada disciplinar, saber o ciencia. La religión no solo ha sido objeto de la filosofía y de la teología, sino que también ha despertado el interés de la sociología y de la psicología, del arte y la literatura, de la historia y el derecho, de la arquitectura y de la educación, y de otros tantos saberes. Este interés no solo es un postulado epistemológico abstracto, sino que también se ha expresado históricamente en la constitución y desarrollo de todas estas disciplinas $y$, en particular en nuestra universidad, se ha manifestado en una permanente práctica de investigación, docencia y extensión $y$, ahora, en este mismo interés por concurrir a la creación de un centro interdisciplinario. De este modo, es la misma riqueza del fenómeno religioso la que exige la interdisciplinariedad y al mismo tiempo plantea el desafío de una auténtica integración del saber, a fin de que los distintos conocimientos sobre la religión se puedan reconocer en su unidad, se potencien y exijan mutuamente (Ex corde ecclesia, $\mathrm{N}^{\circ} 16$ ).

El Centro de Estudios de la Religión representa para la universidad católica, por una parte, la resultante de un proceso de creación y desarrollo de los últimos años, pero al mismo tiempo un desafío que se proyecta a los tiempos venideros con inquietudes y a la espera de nuevos pasos.

Sobre lo primero, nuestra casa de estudios, cuenta con un importante número de académicos que desde sus propias disciplinas o en colaboración con otros, ya trabajan temas vinculados al fenómeno religioso y con ello, expresan la certeza de la vitalidad de esta como fenómeno distintivo de la cultura, que hoy adquiere visibilidad en el espacio público, político y social. La constitución del Cen- 
tro de Estudios permite reclutar y aglomerar las competencias existentes en nuestra universidad para contemplar los cambios culturales que hoy vivenciamos y que han modificado las pautas en que las personas se comprenden a sí mismas, relacionan con otros, pero sobre todo en la relación con lo trascendente, con Dios. Ello exige una comprensión y aproximación que se levante desde los propios actores, con categorías propias, enraizadas en nuestras tradiciones históricas, artísticas y culturales, de ahí la relevancia de contar con un espacio de discusión a nivel local que se constituya en referente a nivel nacional y latinoamericano.

Asimismo, el Centro de Estudios de la Religión ofrece un espacio para que la religión pueda ser discernida en diálogo no solamente interdisciplinar, sino también interreligioso. En palabras del propio Santo Padre Francisco "el diálogo interreligioso es una condición necesaria para la paz en el mundo, y por lo tanto, es un deber para los cristianos así como para otras comunidades religiosas" (Evangelii gaudium, n.250). Es nuestra propia identidad católica la que nos demanda pensar la religión más allá de las fronteras visibles de nuestra propia confesión religiosa. Esto nos permite reconocer el amor incondicionado de
Dios por todos los hombres y nos posibilita acoger con humildad la Verdad que nos transforma y conduce la historia hacia su plenitud, a fin de que Dios sea todo en todos (1 Cor 15,28; cf. Aparecida, $\mathrm{N}^{\circ}$ 237).

Actualmente el Centro lo conforman 9 facultades de nuestra universidad: Artes; Ciencias Sociales; Comunicaciones; Derecho; Educación; Filosofía; Historia, Geografía y Ciencia Política; Letras; y Teología. Desde las cuales se desprenden diversas líneas que se orientan en torno a tres grandes polos de trabajo: docencia, investigación y vinculación con el medio.

En el ámbito de docencia, este año se dicta la segunda versión del diplomado en ciencias de la Religión. Es un espacio formativo destinado a un público diverso; sociólogos, teólogos, filósofos, periodistas, abogados, psicólogos, historiadores y otros profesionales interesados en el tema.

Este diplomado está estructurado en cinco cursos, que abordan el fenómeno religioso desde diversas perspectivas. El primer curso se ha titulado "Introducción al Estudio de la Religión” y explora la importancia y desarrollo que han tenido los estudios sobre la religión en las diferentes ciencias (sociales, jurídicas, filosóficas, literarias, etc.); 
el segundo curso versa sobre una "Historia de las religiones no cristianas", en el que se adquiere una visión global sobre los principales contenidos de las grandes religiones como el Hinduismo, Budismo, Judaísmo e Islam; el tercer curso, bajo el título "Historia del Cristianismo y Desafío Ecuménico" aborda el movimiento ecuménico, su historia, repercusiones sociales, avances y desafíos, particularmente en Chile y América Latina; el cuarto curso "Religiosidad popular en América Latina”, busca comprender el fenómeno religioso desde sus expresiones devocionales populares tanto tradicionales/ancestrales como actuales; el quinto curso "Religión en el mundo moderno" acoge los principales desafíos que la modernidad plantea a la religión, para terminar con el sexto curso "Religión en el Espacio Público" en que se atiende al desafío que implica para las religiones el proceso de secularización y las condiciones y posibilidades que ellas tienen de ser protagonistas en el espacio público en aportes tan fundamentales como la defensa y promoción de los derechos humanos.

Dentro del ámbito de docencia se proyecta la creación de cursos y la constitución de un certificado académico que dé respuestas a las necesidades formativas ad-intra.

En materia de Investigación, las instancias son diversas, desde la constitución estable de núcleos de trabajo que actualmente están ocupándose de temas como; derechos humanos y religión, creencias y jóvenes, religión y libertad religiosa, religión y psicología, como también la constitución de un espacio para investigadores asociados al Centro e interesados en las temáticas de las ciencias de la religión desde sus propias disciplinas. El Centro busca también promover la investigación del fenómeno religioso en estudiantes de postgrado a través de una beca para doctorado y la conformación de un espacio para investigadores jóvenes.

Finalmente, en extensión, el gran desafío de este año es la preparación de un Congreso Internacional a realizarse los días 11,12 y 13 de octubre, bajo la convocatoria "Religión y Espacio Público" el que pretende reunir a investigadores de diversas disciplinas y países que se encuentren trabajando en torno a esta temática.

Patricia Imbarack Facultad de Educación Pontificia Universidad Católica de Chile 